\title{
Herbert Screw Technique for Treating Oblique Mandibular Parasymphysis Fracture: A Case Report
}

Priyanka K*, Sridhar Reddy G, Rajasehkar Gali G, Kishore Kumar RV, Satyakumar D

Department of Oral and Maxillofacial Surgery, Narayana Dental College and Hospital, Chintareddypalem, Nellore- Andhra Pradesh, India

DOI: $10.36347 /$ sjds.2020.v07i03.003

| Received: 03.03.2020 | Accepted: 10.03.2020 | Published: 13.03.2020

*Corresponding author: K. Priyanka

Abstract

Case Report

Mandibular parasymphysis fracture patients are largely managed by definitive surgical management and occasionally by conservative means. Oblique fractures management in the parasymphysis region is quite challenging with miniplate fixation as they are monocortical, and postoperative stability of fracture fragments is questionable, which warrants maxillomandibular fixation(MMF) postoperatively. Interfragmentary mobility plays an important role in bone healing, and MMF impedes early functional rehabilitation. Lag screws offer better stability and eliminate the need for MMF, but with some disadvantages like high compressive forces exerted by the head of the screw. Herbert screw, which is a headless screw, works on the lag principle which eliminates the disadvantage of the lag screw. We present an overview of Herbert Screw in the management of oblique fracture illustrated by a relevant case of trauma. A 28 year old male patient sustained injury in a road traffic accident reported to the Department of Maxillofacial surgery, diagnosed to have oblique mandibular parasymphysis fracture on clinical and radiological examination was successfully treated with. Herbert screw. Though it is a novel treatment technique, it requires methodical treatment planning and surgical proficiency.

Keywords: Herbert screw, oblique fracture of mandibular parasymphysis.

Copyright @ 2020: This is an open-access article distributed under the terms of the Creative Commons Attribution license which permits unrestricted use, distribution, and reproduction in any medium for non-commercial use (NonCommercial, or CC-BY-NC) provided the original author and source are credited.

\section{INTRODUCTION}

Mandible is the most prominent and frequently fractured bone in the maxillofacial region. The therapeutic goal of management of the mandibular fracture is to restore to its original anatomic form and function, with minimal complications.

The treatment modalities for mandibular fractures include closed reduction and open reduction, the former being the most widely accepted. Lag screws, which were based on the principle of axial compression of bone fragments, were used for the management of oblique fractures [1]. They provided the advantage of minimum implant material and maximum stability. But the disadvantage is high compressive forces exerted by the head of the screw.

Herbert and Fischer introduced a headless screw with differential pitch and a blank shaft, which was used in scaphoid bone fracture [2]. This screw was used in the maxillofacial region to address the disadvantage of the lag screw head, which interfered over the external surface of the mandible [3].
This article reports the management of an oblique mandibular parasymphysis fracture treated successfully with Herbert screw.

\section{CASE REPORT}

A 46-year-old male patient reported with a history of RTA. The patient's medical history was unremarkable. Clinical and radiological examination revealed mandibular right parasymphysis fracture, which was oblique in pattern. Open reduction and internal fixation with Herbert screw was performed under general anesthesia.

\section{Surgical procedure}

A vestibular incision was placed mucoperiosteal flap elevated, fracture site exposed, mobilized, and reduced. Occlusion was achieved by maxillomandibular fixation (MMF). Herbert screw was placed to fix the oblique fracture. Initially, the $2 \mathrm{~mm}$ drill bit was used for both the cortices followed by a guidewire used to check the direction of the drill. Later a $2.7 \mathrm{~mm}$ drill bit was used. Over this, a $3.5 \mathrm{~mm}$ tap was used for the lingual cortex, followed by a $4.5 \mathrm{~mm}$ tap for the buccal segment alone. The cannulated internal helix screwdriver was used for flushing with the bone. 
Priyanka K et al., Sch J Dent Sci, March, 2020; 7(3): 57-59

The fractured segments were assessed for mobility. After hemostasis was achieved, layered closure was done. Postoperative orthopantomogram and occlusal radiographs were taken to reveal the position of screws.
Dimensions of the Herbert screw are shaft diameter $3 \mathrm{~mm}$, buccal thread diameter $4.5 \mathrm{~mm}$, and lingual thread diameter $3.5 \mathrm{~mm}$.

\section{PRE OP}
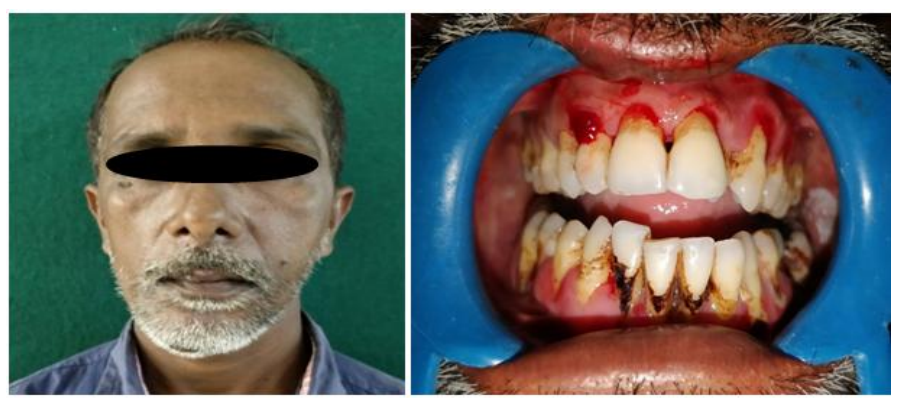

Intra op

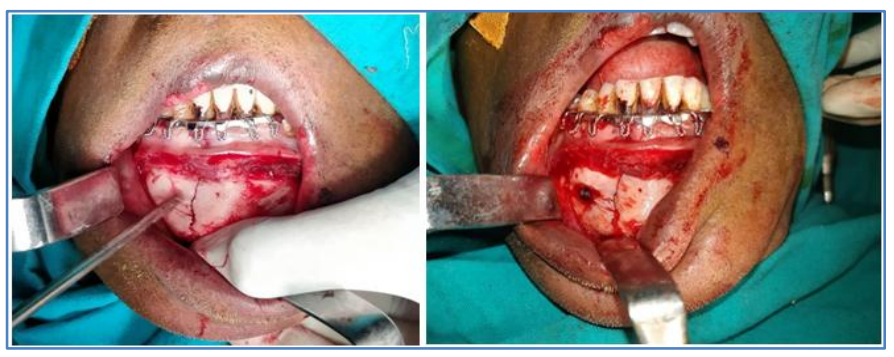

OPG
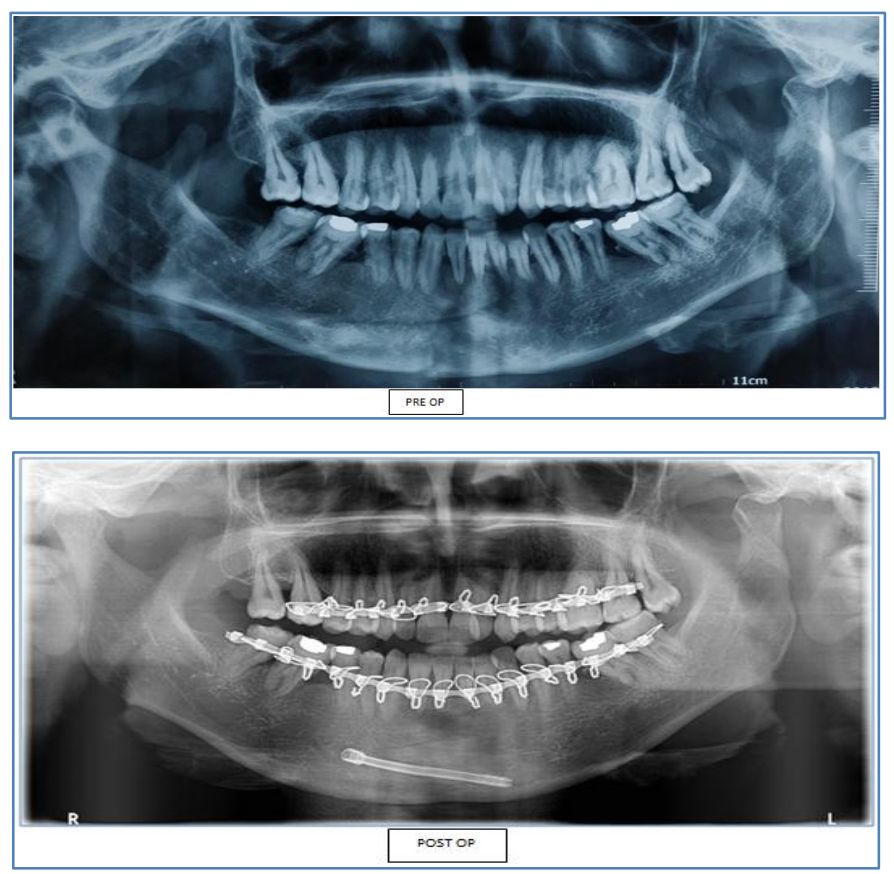

\section{Occlusal radiographs}

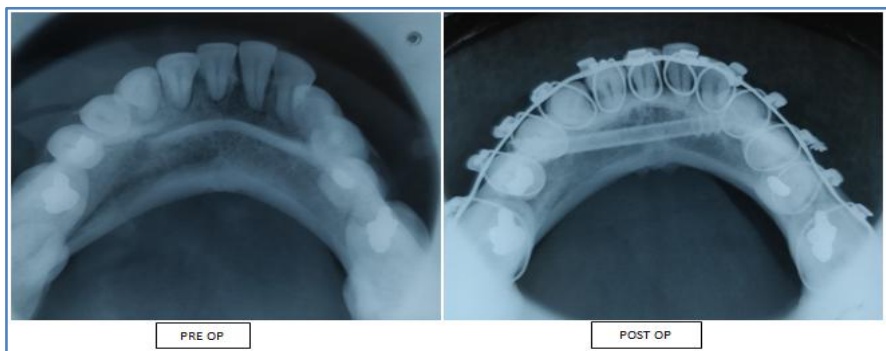




\section{OCCLUSION}

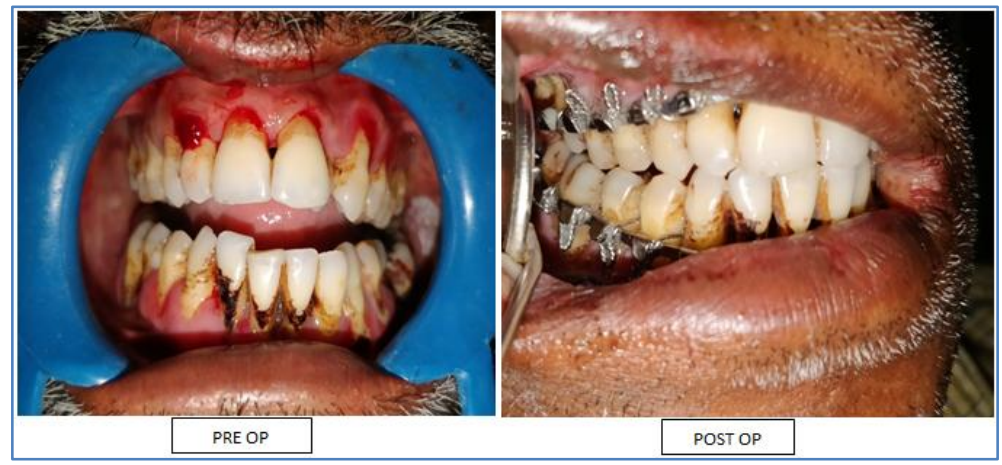

\section{DISCUSSION}

Herbert and Fisher described it as a new method for rigid fixation to manage scaphoid bone fracture. It has since been demonstrated to be a successful and minimally invasive means of providing rigid internal fixation between fracture segments in various terrains of orthopedic surgery.

The Herbert screw produces compression between fragments based on the two differential pitch heads present and not by the head compressing against the outer cortex, as in the case of lag screw [4]. The lag screw also has threads along its entire length, which passes through the fracture segment [5], which can lead to instability along the fracture line and further thread loosening, which is not observed with Herbert screw [3]. The lag screw, being a headed screw, needs to be countersunk so as to be flush with the bone and not cause any undue aesthetic disturbances [6]. The Herbert screw, on the other hand, is a headless screw that omits this additional step and hence, extends its application in particular surfaces as well, such as the TMJ, in the craniomaxillofacial region.

\section{CONCLUSION}

The Herbert screw is an effective and reliable means in the management of oblique fractures in the mandibular parasymphysis region. The advantages of the Herbert screw are its size, which is ideally suited for fixing the small bones; secondly, it does not have a protruding head, so it does not interfere with adjacent soft tissues, and finally, the fact that it is buried within the bone means that it does not have to be removed at a later date.

\section{REFERENCES}

1. Spiessl B. New concepts in maxillofacial bone surgery. Berlin: Springer; 1976.

2. Niederdellmann, H.; Osteosynthesis of mandibular fractures using lag screwsInt. J. Oral Surg. 1976: 5:117-121

3. Herbert TJ, Fisher WE. Management of the fractured scaphoid using a new bone screw. J Bone Joint Surg. 1984; 66-B: 114-23

4. Kotrashetti S, Singh A. Prospective study of treatment outcomes with lag screw versus. Herbert screw fixation in mandibular fractures. Int J Oral Maxillofac Surg. 2017; 46:54-8.

5. Gruszka DS, Burkhart KJ, Nowak TE. The durability of the intrascaphoid compression of headless compression screws: in vitro study. J Hand Surg Am. 2012; 37:1142-50.

6. Kallela I, Ilzuka T, Laine P, Lindquist C. Lagscrew fixation of mandibular parasym-physeal and angle fractures. Oral Surg Oral Med Oral Pathol Oral RadiolEndod. 1996; 82:510-6.

7. Lakota RA. Fixation of dicapitular fractures of the mandibular condyle with a headless bone screw. $\mathrm{Br}$ J Oral Maxillofac Surg. 2007; 45:399-401.

8. El-Mahallawy Y, Herbert cannulated bone screw osteosynthesis in anterior mandibular fracturestreatment: a comparative study with lag screw and mini-plate. J. Oral MaxillofacSurg. 2018, 10.1016/j.joms.2018.01.034.

9. Park J-W, Kim K-T, Sung J-K. Biomechanical Comparison of inter-fragmentary Compression Pressures: Lag Screw versus Herbert Screwfor Anterior Odontoid Screw Fixation. J Korean Neurosurg Soc.2017, 60:498-503.

10. Eckart Pilling, MD, Matthias Schneider, MD, Ronald Mai, MD. Minimally Invasive Fracture Treatment with Cannulated Lag Screws in Intracapsular Fractures of the Condyle. J Oral Maxillofac Surg. 64:868-872, 2006. 